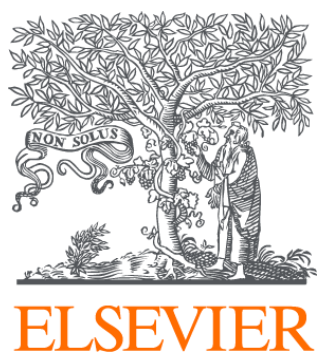

Since January 2020 Elsevier has created a COVID-19 resource centre with free information in English and Mandarin on the novel coronavirus COVID-

19. The COVID-19 resource centre is hosted on Elsevier Connect, the company's public news and information website.

Elsevier hereby grants permission to make all its COVID-19-related research that is available on the COVID-19 resource centre - including this research content - immediately available in PubMed Central and other publicly funded repositories, such as the WHO COVID database with rights for unrestricted research re-use and analyses in any form or by any means with acknowledgement of the original source. These permissions are granted for free by Elsevier for as long as the COVID-19 resource centre remains active. 


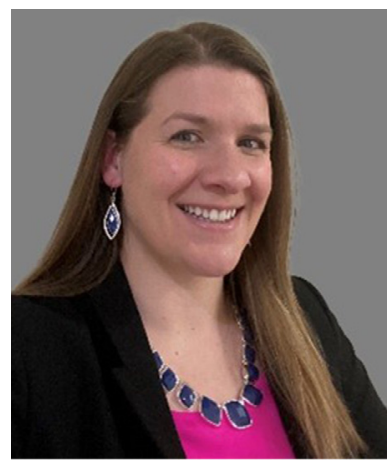

\title{
Novel technologies for vaccine development
}

\author{
Kaitlyn M. Morabito
}

DMID, NIAID, NIH, USA

Traditional vaccine development involves starting with the virus or pathogen and developing vaccines based on empirical evaluation. Most licensed vaccines currently fall within this category including whole-inactivated vaccines, live-attenuated vaccines that have been attenuated through passage methods, or proteins that have been purified from virus preparations, or produced in vitro using wild-type sequences. In contrast, rational vaccine design starts with knowledge of protective or presumably protective immune responses against a virus and designing vaccines to elicit that specific immune response. The recent shift towards rational vaccine designs has been enabled by the development of new technology. These transforming technologies include structure-based vaccine design, advances in sorting, sequencing and bioinformatics which enable a more in-depth analysis of immune responses, and rapid DNA synthesis which allows more rapid high-throughput evaluation of monoclonal antibodies and screening of antigens. Additionally, advances in gene editing have enhanced transgenic or humanized mouse models for vaccine evaluation and technologies for gene-based delivery of vaccine antigens have also improved. The development of these technologies has improved both the precision of vaccines by shifting the balance towards protective immune responses and away from non-protective responses, and the speed at which the immune response can be analyzed, and vaccines can be evaluated and manufactured. Rational vaccine design provides new solutions to old problems such as RSV and influenza, enables rapid response to emerging pathogens such as SARS-CoV2, and has the potential to improve vaccine safety for pathogens such as dengue virus. 